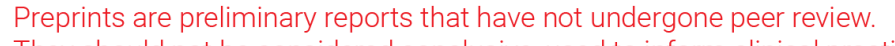 \\ They should not be considered conclusive, used to inform clinical practice, or referenced by the media as validated information. \\ The effect of trastuzumab on taxane-induced peripheral neuropathy in women with breast cancer: a population-based cohort study
}

\section{Ruchit Patel}

Queen's University

Josee Lyne-Ethier

Kingston Health Sciences Centre

\section{Susan Brogly}

Kingston Health Sciences Centre

\section{Rebecca Griffiths}

Institute for Clinical Evaluative Sciences

J. Michael Hendry ( $\nabla$ Michael.hendry@kingstonhsc.ca )

Kingston Health Sciences Centre

\section{Research Article}

Keywords: Trastuzumab, Taxanes, Peripheral Neuropathy, Breast Cancer, ErbB2, Neuroprotection, Health Database

Posted Date: January 18th, 2022

DOI: https://doi.org/10.21203/rs.3.rs-1254626/v1

License: (1) This work is licensed under a Creative Commons Attribution 4.0 International License.

Read Full License 


\section{Abstract}

Background: Recent pre-clinical evidence suggests a protective role of trastuzumab following nerve injury. Therefore, a population-based database study was utilized to examine whether trastuzumab can prevent taxane-induced peripheral neuropathy (TIPN).

Methods: We performed a population-based retrospective cohort study to evaluate the neuroprotective effect of trastuzumab. The population-level cohort for this study included all incident cases of breast cancer diagnosed in Ontario from January 1, 2007-December 31, 2017 in patients aged $\geq 66$ years who received taxane (paclitaxel or docetaxel) chemotherapy. There were no restrictions on specific paclitaxel or docetaxel regimens. Two years of follow-up data were available for all patients. The primary outcome was incident neuropathic pain which was measured by the number of new prescriptions commonly used as first-line treatments for neuropathic pain. The secondary outcome was healthcare utilization related to peripheral neuropathy. Healthcare utilization was characterized as outpatient visits, emergency department visits, and hospitalizations.

Results: We included 3905 patients (> 66 years old) with stage I-III breast cancer treated with taxanecontaining chemotherapy (paclitaxel/docetaxel) regimens between 2007-2017. 74\% patients received taxane-based chemotherapy alone, while $26 \%$ received taxane-based chemotherapy plus trastuzumab. Only $4 \%$ of patients received treatment for TIPN for more than 6 months. The incidence of neuropathic pain medication prescription was lower in the paclitaxel plus trastuzumab group when compared to the paclitaxel only group ( $15.1 \%$ vs $20.5 \%, p=0.026)$. There was no difference in the proportion of patients who needed emergency department visits, hospitalizations, or outpatient visits for neuropathy symptoms between the two groups.

Conclusions: These findings provide a real-world estimate of clinically significant TIPN and evidence of a small protective effect conferred by trastuzumab against these symptoms.

\section{Background}

Chemotherapy-induced peripheral neuropathy (CIPN) is a common adverse effect of cancer therapy that significantly diminishes the quality of life $(1)$, impairs daily function $(2,3)$ and is associated with higher healthcare costs and resource utilization (4). The taxane chemotherapeutic drugs paclitaxel and docetaxel are part of standard systemic treatment for early breast cancer, as patients with non-metastatic (stage I-III) breast cancer who require chemotherapy are typically treated with anthracycline- and taxanecontaining $3^{\text {rd }}$ generation regimens (5). Unfortunately, these agents are associated with a high incidence of CIPN, with upwards of $50 \%$ of patients affected (6). In the Canadian province of Ontario, commonly used $3^{\text {rd }}$ generation chemotherapy regimens include 5 -fluorouracil, doxorubicin, and cyclophosphamide every three weeks for three cycles, followed by docetaxel $100 \mathrm{mg} / \mathrm{m}^{2}$ every three weeks for three cycles (FEC-D; total docetaxel dose $300 \mathrm{mg} / \mathrm{m}^{2}$ ) and dose-dense doxorubicin and 
cyclophosphamide every two weeks for four cycles followed by paclitaxel $175 \mathrm{mg} / \mathrm{m}^{2}$ every two weeks for four cycles (ddAC-T; total paclitaxel dose $700 \mathrm{mg} / \mathrm{m}^{2}$ ).

In human epidermal growth factor receptor 2 (HER-2) positive breast cancers, the monoclonal antibody trastuzumab (Herceptin ${ }^{\circledR}$ ) is administered as part of standard care, commencing concurrently with taxane chemotherapy and continuing every three weeks for a total of 1 year (7). The overall incidence of all grades of CIPN with paclitaxel and docetaxel ranges from $57-83 \%$ and $11-64 \%$ respectively (8). While the severity of CIPN associated with these taxane agents depends on various factors, including the chemotherapy regimen, cumulative dose, and patient characteristics, paclitaxel is generally considered more neurotoxic than docetaxel $(9,10)$. CIPN associated with these taxane derivates not only diminishes the quality of life, but also leads to chemotherapy dose reduction, modification and/or premature treatment discontinuation, all of which can adversely affect treatment outcomes (11-14).

The mechanisms underlying the development of CIPN are multifactorial and not fully understood. Current data suggests that alterations in axonal transport, mitochondrial function and/or $\mathrm{Ca}^{2+}$ homeostasis lead to direct or indirect axonal degeneration ${ }^{10}$. These pathways are also shared with the mechanism of action of taxane chemotherapy ${ }^{11}$. At present, treatment for CIPN focuses on lessening symptoms, as there are no current therapies that address the underlying mechanisms $(16,17)$. Anticonvulsants such as gabapentin and pregabalin, in addition to tricyclic antidepressants and serotonin-norepinephrine reuptake inhibitors, are examples of several drug classes that are used to treat symptoms of CIPN ${ }^{13}$.

Recently, it has been shown that trastuzumab can enhance recovery following peripheral nerve injury in pre-clinical models through its action on the ErbB2 receptor, the rodent homologue to HER2 $(18,19)$. This effect is hypothesized to occur by preventing the inhibitory transactivation of EGFR, a known negative regulator of peripheral nerve regeneration, by $\operatorname{ErbB} 2(20,21)$. Given these promising effects in pre-clinical nerve injury models, we sought to examine its influence on peripheral nerves in humans. Accordingly, we hypothesized that the co-administration of neurotoxic taxane chemotherapy and potentially neuroprotective trastuzumab may lead to a reduced incidence of peripheral neuropathy in women undergoing treatment for breast cancer. We tested this hypothesis by performing a population-based cohort study of patients with early-stage breast cancer who received taxane-containing chemotherapy with or without trastuzumab.

\section{Methods}

\section{Study Design and Population}

We performed a population-based retrospective cohort study to evaluate the neuroprotective effect of trastuzumab amongst breast cancer patients who received taxane-based chemotherapy with or without trastuzumab in Ontario, Canada. The study was approved by the Research Ethics Board of Queen's University, Kingston, Canada. 
The population-level cohort for this study included all incident cases of breast cancer diagnosed in Ontario from January 1, 2007-December 31, 2017 in patients aged $\geq 66$ years who received taxane (paclitaxel or docetaxel) chemotherapy. There were no restrictions on specific paclitaxel or docetaxel regimens, and both neoadjuvant as well as adjuvant regimens were included. Two years of follow-up data were available for all patients. Patients were excluded if they did not have Ontario Health Insurance Plan (OHIP) coverage for two years before and/or after the date of incident, had stage IV cancer, were male, or had a prior history of documented peripheral neuropathy. The index group was patients with HER2-positive breast cancer who received taxane chemotherapy (paclitaxel- and/or docetaxel-based regimens) and trastuzumab. The reference group included patients who received only taxane chemotherapy (paclitaxel- and/or docetaxel-based regimens) as part of their cancer treatment.

\section{Data Sources}

We accessed the following administrative health databases in conjunction with ICES (www.ices.on.ca) to derive data for our study population: (1) Ontario Cancer Registry; (2) Registered Persons Database; (3) OHIP Claims Database; (4) Ontario Drug Benefit Claims Database; (5) New Drug Funding Program Database; (6) Discharge Abstract Database; and (7) National Ambulatory Care Reporting System. ICES is an independent, non-profit research institute whose legal status under Ontario's health information privacy law allows it to collect and analyze health care and demographic data, without consent, for health system evaluation and improvement.

The Ontario Cancer Registry is a registry that passively accumulates diagnostic and demographic information of at least $98 \%$ of incident cases of cancer in the province (22). Baseline demographic information including age at diagnosis, sex, place of residence at diagnosis, socioeconomic status at diagnosis and date of death (where applicable) was identified from the Registered Persons Database. Medication prescriptions and chemotherapy administration were identified from the OHIP Claims, Ontario Drug Benefit Claims, Activity Level Reporting and New Drug Funding Program databases. Information about outpatient visits, emergency department (ED) visits, and hospitalizations related to peripheral neuropathy and cardiotoxicity diagnoses were identified from Canadian Institute for Health Information (CIHI) Discharge Abstract Database (DAD) and the National Ambulatory Care Reporting System (NACRS), which are mandatory submissions from hospitals to $\mathrm{ClHI}$.

CIPN is a broad diagnosis and was defined using a comprehensive list of International Classification of Disease (ICD)-9, ICD-10 and OHIP diagnostic codes. The list of diagnostic codes used in this study was adapted from that which was applied successfully in two prior studies at our institution evaluating outcomes of CIPN $(23,24)$. The authors for the present study reviewed the list for suitability to our specific application, revised it accordingly and applied it to our patient cohort.

\section{Study Outcomes}

The primary outcome was incident neuropathic pain. This was measured by the number of new prescriptions commonly used as first-line treatments for neuropathic pain. This particular surrogate 
metric was validated and applied in prior studies evaluating CIPN in colon and testicular cancer $(23,24)$. Using the number of prescriptions as a metric provides real-world insight into the incidence of clinically significant CIPN requiring treatment. These medications included pregabalin, tricyclic antidepressants, gabapentin and duloxetine. These oral agents are all recommended by The American Society of Clinical Oncology to treat symptomatic CIPN (25). The observation window for new neuropathic pain medication prescriptions was one year after the onset of breast cancer treatment. The persistence of neuropathic pain was measured by a second prescription of neuroleptic medications was filled within 6-12 months of the first prescription.

The secondary outcome was healthcare utilization related to peripheral neuropathy. Healthcare utilization was characterized as outpatient visits, ED visits, and hospitalizations. For each patient, health care utilization for peripheral neuropathy was evaluated over a 2-year period from the onset of treatment.

Groups were analyzed first by comparing any taxane treatment (patients that received docetaxel, paclitaxel or both) alone to taxane treatment combined with trastuzumab. Given the differing propensities to developing CIPN between these two drugs, subgroup analysis then compared the same outcomes based on whether patients received docetaxel or paclitaxel. Patients exposed to both docetaxel-and paclitaxel-based regimens were excluded from the taxane-specific analysis.

\section{Statistical Analysis}

Continuous variables were reported as mean \pm standard deviation and were compared by treatment groups using independent t-test or Mann-Whitney $\mathrm{U}$ test. Chi-square test was used to compare categorical variables across groups. All p-values were 2 -sided, with a p-value of less than 0.05 considered statistically significant. All analyses were performed using SAS version 9.4 (SAS Institute, Cary, NC).

\section{Results}

Between 2007 and 2017, 44,143 incident cases of breast cancer were diagnosed in Ontario in patients aged $>65$ years. Of those with stage $\mathrm{I}-\mathrm{III}$ breast cancer receiving taxane-containing chemotherapy, 3905 patients met the inclusion criteria for our study (Figure 1). Amongst this cohort, 73.8\% (2880 patients) received only taxane-based chemotherapy while $26.2 \%$ (1025 patients) received taxane-based chemotherapy plus trastuzumab.

The baseline characteristics of the study cohorts (Table 1) demonstrated that those in the taxane plus trastuzumab group were more likely to have stage I disease $(30.1 \%$ vs $16.5 \%, p<0.001)$ and were more likely to receive a paclitaxel-based chemotherapy regimen ( $35.6 \%$ vs $31.2 \%, p=0.01)$ than those who used taxane only. A higher proportion of patients in the taxane only group had stage II ( $50 \%$ vs $54 \%, p=$ $0.025)$ and stage III $(20 \%$ vs $29.5 \%, p<0.001)$ breast cancer, and were more likely to receive a docetaxelbased chemotherapy regimen $(63 \%$ vs $68 \%, p=0.004)$

\section{Neuropathic Pain Medication Prescriptions}


As shown in Table 2, the incidence of prescriptions for neuropathic pain medication was similar between the taxane plus trastuzumab and taxane only groups $(11.9 \%$ vs $12 \%, p>0.05)$. Likewise, persistent neuropathy, defined as a second prescription for neuropathic pain medications within 6-12 months after the first prescription, was similar between the groups (3.7\% [30/812] vs $4.2 \%$ [101/2433], $p>0.05)$.

In the agent-specific analysis (Table 3 and 4), the incidence of prescriptions for neuropathic pain medication was similar between the docetaxel plus trastuzumab and docetaxel only groups $(9.9 \%$ vs $8.2 \%, p>0.05)$. Likewise, persistent neuropathy was similar between these groups $(2.5 \%$ vs $2.7 \%, p>$ $0.05)$. However, the incidence of neuropathic pain medication prescription was lower in the paclitaxel plus trastuzumab group when compared to the paclitaxel only group $(15.1 \%$ vs $20.5 \%, p=0.026)$. Persistent neuropathy was similar between these groups $(6.2 \%$ vs $7.7 \%, p>0.05)$. The average number of prescriptions for neuropathic medication prescribed between groups within 1 year were not statistically different in any of the analyses.

\section{Healthcare Utilization}

Figure 2 compares healthcare utilization related to peripheral neuropathy between the taxane only and taxane plus trastuzumab groups. The number of ED visits related to neuropathy was not different between the two groups: $3.8 \%$ of patients in the taxane plus trastuzumab group had 1-3 ED visits compared to $3.6 \%$ of the patients in the taxane only group. The remainder of the patients in the taxane plus trastuzumab group and the taxane only group had no ED visits related to neuropathy. Likewise, the number of hospital admissions for neuropathy did not differ between the taxane plus trastuzumab and the taxane-only groups. Most patients in either group had no visits $(97.9 \%$ vs $98.7 \%)$ or $1-3$ visits (2.1\% vs $1.3 \%)$. There was also no difference in the number of patients attending none, 1 , or more than 1 outpatient visit between taxane plus trastuzumab and taxane only groups.

Figure 3 compares healthcare utilization related to peripheral neuropathy between the docetaxel plus trastuzumab and docetaxel only groups. The number of ED visits related to neuropathy was not different between these two groups: $3.4 \%$ of patients in the docetaxel plus trastuzumab group had 1-2 ED visits compared to $3.3 \%$ of the patients in the docetaxel only group. The remainder of the patients had no ED visits related to neuropathy. Likewise, the number of hospital admissions for neuropathy was not significantly different between the docetaxel plus trastuzumab and docetaxel only groups. Most patients in either group had no hospitalization $(98.3 \%$ vs $98.6 \%, p>0.05)$ or $1-2$ hospitalizations $(1.7 \%$ vs $1.4 \%$; $p$ > 0.05). There was also no difference in the number of patients attending zero, 1 or more than 1 outpatient visits between docetaxel plus trastuzumab and docetaxel only groups $(p>0.05)$.

Figure 4 compares healthcare utilization related to peripheral neuropathy between the paclitaxel plus trastuzumab and paclitaxel only groups. The number of ED visits related to neuropathy was not different between these two groups: $4.9 \%$ of patients in the paclitaxel plus trastuzumab group had 1-3 ED visits compared to $4.6 \%$ of the patients in the paclitaxel only group. The remainder of the patients had no ED visits related to neuropathy. Likewise, the number of hospital admissions for neuropathy was not significantly different between the paclitaxel plus trastuzumab and paclitaxel only groups. Most patients 
in either group had no hospitalizations ( $96.8 \%$ vs $98.7 \%, p>0.05$ ) or 1-3 hospitalizations (3.2 vs $1.3 \%$; $p$ > 0.05). There was also no difference in the number of patients attending zero, 1 or more than 1 outpatient visits between paclitaxel plus trastuzumab and paclitaxel only groups $(p>0.05)$.

\section{Discussion}

CIPN is a dose-limiting complication that can arise among those receiving taxane chemotherapy (11). Currently, there are no effective strategies that prevent or reverse the occurrence of CIPN and efforts to find one has significant therapeutic potential. Preclinical studies of nerve injury suggest that trastuzumab may have a protective effect against the development of CIPN. Therefore, this study compared the incidence of taxane-induced peripheral neuropathy with or without receipt of trastuzumab within a large, homogenous cohort of women with breast cancer by using population-wide administrative health databases.

We observed that trastuzumab led to a statistically significant reduction in the incidence of peripheral neuropathy amongst patients who were treated with a paclitaxel-based regimen for non-metastatic breast cancer. This was no difference amongst the patients who were treated with a docetaxel-based regimen or the docetaxel and paclitaxel groups were combined. Secondly, we generated real-world insight into the natural history of taxane induced peripheral neuropathy by demonstrating treatment rates of $12 \%$ with first line medications. Further, we showed that two-thirds of the patients with taxane induced peripheral neuropathy did not require treatment beyond 6 months of taxane initiation. Thirdly, we observed emergency department visits and hospitalization rates of $3.7 \%$ and $1.5 \%$, respectively, indicating the potential severity of this adverse effect of taxane chemotherapy in a small group of patients.

While the effect of trastuzumab was significant amongst patients receiving a paclitaxel-based regimen, this effect was not present with multivariate analysis (Table 5). There are several explanations for this observation and the lack of observed effect with trastuzumab among patients receiving docetaxel. The use of administrative health databases relies on accurate and consistent coding of Ontario diagnostic, ICD-9 and ICD-10 codes applicable to each patient encounter. Despite our use of a previously validated coding scheme for our definition of peripheral neuropathy $(23,24)$, we acknowledge this inherent limitation with administrative health databases. Second, the development of CIPN is closely related to the patient's cumulative dose(26). It is unknown whether our groups were balanced with respect to cumulative dose, dose per cycle, number of cycles, dose reductions and treatment schedule; these data were not available. Finally, a protective effect of trastuzumab may obscure its own detection by allowing a greater proportion of patients to endure a higher cumulative dose and toxicity. The latter effect could be explored in a future study by comparing the number of patients who had dose reduction or premature termination of treatment between groups.

Our study revealed consistent estimates of the incidence of taxane-induced peripheral neuropathy of approximately $12 \%$ when measured using the number of new prescriptions for first-line neuropathy medications. When looking at specific taxanes, we observed the incidence of docetaxel- and paclitaxel- 
induced peripheral neuropathy to be $8.6 \%$ and $18.9 \%$, respectively. The higher incidence of neuropathy with paclitaxel compared with docetaxel is consistent with trends observed in the literature (57-83\% for paclitaxel; $11-64 \%$ for docetaxel(8)), however the risk in our study tended to be lower. This heterogeneity could be explained by differences in taxane schedules, cumulative dose and the methods used to assess peripheral neuropathy (27). Schneider et al. (2012) observed a total rate of grade 2-4 peripheral neuropathy in the non-metastatic adjuvant setting of $16.9 \%$, closer to our observed incidence of $12 \%(28)$.

Studies regarding the persistence of taxane-induced peripheral neuropathy are also varied. Hershman and colleagues (2014) found that $81 \%$ of patients with early-stage breast cancer experienced symptoms of neuropathy up to 2 years post-adjuvant taxane therapy, with up to $27 \%$ reporting severe symptoms in the hands and feet (29). In another study, it was found that taxane-induced peripheral neuropathy persisted in $41 \%$ of patients at 3 years after initiation of treatment (30). Despite these indications of persistent neuropathy affecting a considerable number of patients, our study suggests that only a minority $(4 \%)$ have symptoms persistent enough to require prolonged treatment beyond 6 months. This is consistent with reports of similar patient cohorts identifying that $4.8 \%$ of breast cancer patients treated with taxane chemotherapy continue to require treatment at 12 months (31).

\section{Conclusion}

This study examined a potential neuroprotective effect of trastuzumab against taxane induced peripheral neuropathy using administrative health databases. Patients receiving trastuzumab concurrently with paclitaxel were found to have a decrease in the number of prescriptions for first line medications for peripheral neuropathy. Similar observations were not seen in docetaxel and combined (docetaxel or paclitaxel) groups, but may also reflect the inherent limitations in using population wide administrative health databases. The observed treatment rates and duration may also inform provider counselling of their patients.

\section{Abbreviations}

TIPN - Taxane-induced peripheral neuropathy

CIPN - Chemotherapy-induced peripheral neuropathy

HER-2 - Human epidermal growth factor receptor 2

OHIP - Ontario Health Insurance Plan

ED - emergency department (ED) visits

$\mathrm{ClHI}$ - Canadian Institute for Health Information (ClHI)

DAD - Discharge Abstract Database (DAD) 
MACRS - National Ambulatory Care Reporting System (NACRS)

ADG - Aggregated Diagnosis Group

\section{Declarations}

\section{Ethical Approval and Consent to participate}

The study was approved by the Research Ethics Board of Queen's University, Kingston, Canada.

REB Project Identification Number: \#6029163

\section{Consent for publication}

Not applicable

\section{Availability of supporting data}

The datasets constructed with the use of the ICES database are unavailable for sharing.

\section{Competing Interests}

$\mathrm{RP}, \mathrm{SB}, \mathrm{RG}$ and JMH declare that they have no competing interests. JE reports personal fees from AstraZeneca, Merck and GlaxoSmithKline outside the submitted work (no direct conflict with this research/manuscript).

\section{Funding}

This work was supported by funding provided by the Queen's University Department of Surgery.

\section{Authors' contributions}

RP contributed to data interpretation and drafted the manuscript. SB contributed to protocol development, data analysis, data interpretation and revision of the manuscript. JE contributed to protocol development, data analysis, data interpretation and revision of the manuscript. RG contributed to data collection, data analysis and revision of the manuscript. JMH is the principal investigator and contributed to protocol development, data analysis, data interpretation, manuscript preparation and revision.

\section{Acknowledgements}

The authors acknowledge and thank the support provided by ICES to facilitate this study and funding provided by the Queen's University Department of Surgery. We are also thankful to the publicly accessible Cancer Care Ontario (CCO) and the $\mathrm{ClHI}$ databases.

This study was supported by ICES, which is funded by an annual grant from the Ontario Ministry of Health (MOH) and the Ministry of Long-Term Care (MLTC). The opinions, results and conclusions reported 
in this paper are those of the authors and are independent from the funding sources. No endorsement by ICES, the MOH or MLTC is intended or should be inferred.

Parts of this material are based on data and information provided by CCO. The opinions, results, views, and conclusions reported in this paper are those of the authors and do not necessarily reflect those of CCO. No endorsement by CCO is intended or should be inferred.

Parts of this material are based on data and/or information compiled and provided by $\mathrm{ClHI}$. However, the analyses, conclusions, opinions and statements expressed in the material are those of the author(s), and not necessarily those of $\mathrm{ClHI}$.

\section{References}

1. Mols F, Beijers T, Vreugdenhil G, van de Poll-Franse L. Chemotherapy-induced peripheral neuropathy and its association with quality of life: a systematic review. Support Care Cancer. 2014 Aug;22(8):2261-9.

2. Bakitas MA. Background noise: The experience of chemotherapy-induced peripheral neuropathy. Nursing Research. 2007;

3. Gewandter JS, Fan L, Magnuson A, Mustian K, Peppone L, Heckler C, et al. Falls and functional impairments in cancer survivors with chemotherapy-induced peripheral neuropathy (CIPN): a University of Rochester CCOP study. Support Care Cancer. 2013 Jul;21(7):2059-66.

4. Pike CT, Birnbaum HG, Muehlenbein CE, Pohl GM, Natale RB. Healthcare Costs and Workloss Burden of Patients with Chemotherapy-Associated Peripheral Neuropathy in Breast, Ovarian, Head and Neck, and Nonsmall Cell Lung Cancer. Chemotherapy Research and Practice. 2012 Mar 14;2012:1-10.

5. Early Breast Cancer Trialists' Collaborative Group (EBCTCG). Comparisons between different polychemotherapy regimens for early breast cancer: meta-analyses of long-term outcome among 100000 women in 123 randomised trials. The Lancet. 2012 Feb;379(9814):432-44.

6. Zajączkowska R, Kocot-Kępska M, Leppert W, Wrzosek A, Mika J, Wordliczek J. Mechanisms of Chemotherapy-Induced Peripheral Neuropathy. IJMS. 2019 Mar 22;20(6):1451.

7. National Comprehensive Cancer Network. Breast Cancer [Internet]. 2021. Available from: https://www.nccn.org/professionals/physician_gls/pdf/breast.pdf

8. Velasco R, Bruna J. Taxane-Induced Peripheral Neurotoxicity. Toxics. 2015 Apr 28;3(2):152-69.

9. Kudlowitz D, Muggia F. Defining Risks of Taxane Neuropathy: Insights from Randomized Clinical Trials. Clin Cancer Res. 2013 Sep 1;19(17):4570-7.

10. Kerckhove N, Collin A, Condé S, Chaleteix C, Pezet D, Balayssac D. Long-Term Effects, Pathophysiological Mechanisms, and Risk Factors of Chemotherapy-Induced Peripheral Neuropathies: A Comprehensive Literature Review. Front Pharmacol [Internet]. 2017 Feb 24 [cited 2021 May 23];8. Available from: http://journal.frontiersin.org/article/10.3389/fphar.2017.00086/full 
11. Speck RM, Sammel MD, Farrar JT, Hennessy S, Mao JJ, Stineman MG, et al. Impact of Chemotherapy-Induced Peripheral Neuropathy on Treatment Delivery in Nonmetastatic Breast Cancer. JOP. 2013 Sep;9(5):e234-40.

12. Bhatnagar B, Gilmore S, Goloubeva O, Pelser C, Medeiros M, Chumsri S, et al. Chemotherapy dose reduction due to chemotherapy induced peripheral neuropathy in breast cancer patients receiving chemotherapy in the neoadjuvant or adjuvant settings: a single-center experience. SpringerPlus. 2014;3(1):366.

13. Veitch Z, Khan OF, Tilley D, Tang PA, Ribnikar D, Stewart DA, et al. Impact of Cumulative Chemotherapy Dose on Survival With Adjuvant FEC-D Chemotherapy for Breast Cancer. Journal of the National Comprehensive Cancer Network. 2019 Aug;17(8):957-67.

14. Socinski MA, Schell MJ, Peterman A, Bakri K, Yates S, Gitten R, et al. Phase III trial comparing a defined duration of therapy versus continuous therapy followed by second-line therapy in advancedstage IIIB/IV non-small-cell lung cancer. Journal of clinical oncology: official journal of the American Society of Clinical Oncology. 2002 Mar;20(5):1335-43.

15. Fukuda Y, Li Y, Segal RA. A Mechanistic Understanding of Axon Degeneration in ChemotherapyInduced Peripheral Neuropathy. Front Neurosci. 2017 Aug 31;11:481.

16. Majithia N, Temkin SM, Ruddy KJ, Beutler AS, Hershman DL, Loprinzi CL. National Cancer Institutesupported chemotherapy-induced peripheral neuropathy trials: outcomes and lessons. Support Care Cancer. 2016 Mar;24(3):1439-47.

17. Brewer JR, Morrison G, Dolan ME, Fleming GF. Chemotherapy-induced peripheral neuropathy: Current status and progress. Gynecologic Oncology. 2016 Jan;140(1):176-83.

18. Hendry JM, Alvarez-Veronesi MC, Placheta E, Zhang JJ, Gordon T, Borschel GH. ErbB2 blockade with Herceptin (trastuzumab) enhances peripheral nerve regeneration after repair of acute or chronic peripheral nerve injury: Herceptin and Regeneration. Ann Neurol. 2016 Jul;80(1):112-26.

19. Placheta E, Hendry JM, Wood MD, Lafontaine CW, Liu EH, Cecilia Alvarez Veronesi M, et al. The ErbB2 inhibitor Herceptin (Trastuzumab) promotes axonal outgrowth four weeks after acute nerve transection and repair. Neuroscience Letters. 2014 Oct;582:81-6.

20. Koprivica V. EGFR Activation Mediates Inhibition of Axon Regeneration by Myelin and Chondroitin Sulfate Proteoglycans. Science. 2005 Oct 7;310(5745):106-10.

21. Leinster VHL, Joy MT, Vuononvirta RE, Bolsover SR, Anderson PN. ErbB1 epidermal growth factor receptor is a valid target for reducing the effects of multiple inhibitors of axonal regeneration. Experimental Neurology. 2013 Jan;239:82-90.

22. Clarke, EA, Marrett, LD, Kreiger, N. Cancer registration in Ontario: a computer approach. IARC Sci Publ. 1991;

23. Raphael MJ, Fischer HD, Fung K, Austin PC, Anderson GM, Booth CM, et al. Neurotoxicity Outcomes in a Population-based Cohort of Elderly Patients Treated With Adjuvant Oxaliplatin for Colorectal Cancer. Clinical Colorectal Cancer. 2017 Dec;16(4):397-404.e1. 
24. Raphael MJ, Wei X, Karim S, Robinson AG, Bedard PL, Booth CM. Neurotoxicity Among Survivors of Testicular Cancer: A Population-based Study. Clinical Oncology. 2019 Sep;31(9):653-8.

25. Loprinzi CL, Lacchetti C, Bleeker J, Cavaletti G, Chauhan C, Hertz DL, et al. Prevention and Management of Chemotherapy-Induced Peripheral Neuropathy in Survivors of Adult Cancers: ASCO Guideline Update. JCO. 2020 Oct 1;38(28):3325-48.

26. Kanbayashi Y, Hosokawa T, Okamoto K, Konishi H, Otsuji E, Yoshikawa T, et al. Statistical identification of predictors for peripheral neuropathy associated with administration of bortezomib, taxanes, oxaliplatin or vincristine using ordered logistic regression analysis. Anti-Cancer Drugs. 2010 Oct;21(9):877-81.

27. Argyriou AA, Bruna J, Marmiroli P, Cavaletti G. Chemotherapy-induced peripheral neurotoxicity (CIPN): An update. Critical Reviews in Oncology/Hematology. 2012 Apr;82(1):51-77.

28. Schneider BP, Zhao F, Wang M, Stearns V, Martino S, Jones V, et al. Neuropathy Is Not Associated With Clinical Outcomes in Patients Receiving Adjuvant Taxane-Containing Therapy for Operable Breast Cancer. JCO. 2012 Sep 1;30(25):3051-7.

29. Hershman DL, Weimer LH, Wang A, Kranwinkel G, Brafman L, Fuentes D, et al. Association between patient reported outcomes and quantitative sensory tests for measuring long-term neurotoxicity in breast cancer survivors treated with adjuvant paclitaxel chemotherapy. Breast Cancer Res Treat. 2011 Feb;125(3):767-74.

30. Tanabe Y, Hashimoto K, Shimizu C, Hirakawa A, Harano K, Yunokawa M, et al. Paclitaxel-induced peripheral neuropathy in patients receiving adjuvant chemotherapy for breast cancer. Int $\mathrm{J}$ Clin Oncol. 2013 Feb;18(1):132-8.

31. Song SJ, Min J, Suh SY, Jung SH, Hahn HJ, Im S-A, et al. Incidence of taxane-induced peripheral neuropathy receiving treatment and prescription patterns in patients with breast cancer. Support Care Cancer. 2017 Jul;25(7):2241-8.

\section{Tables}

Table 1. Baseline Characteristics of Study Population 


\begin{tabular}{|c|c|c|c|c|c|}
\hline \multicolumn{2}{|l|}{ Characteristic } & Total & $\begin{array}{l}\text { Taxane }+ \\
\text { Trastuzumab }\end{array}$ & $\begin{array}{l}\text { Taxane } \\
\text { only }\end{array}$ & $\begin{array}{l}P \\
\text { value }\end{array}$ \\
\hline \multicolumn{2}{|l|}{ Sample size } & 3,905 & 1,025 & 2,880 & \\
\hline \multicolumn{2}{|c|}{ Age at index date, mean \pm SD } & $\begin{array}{l}71.0 \pm \\
4.14\end{array}$ & $71.6 \pm 4.6$ & $70.8 \pm 3.9$ & $<0.001$ \\
\hline \multicolumn{2}{|l|}{ Diabetes } & $859(22 \%)$ & $231(22.5 \%)$ & $\begin{array}{l}628 \\
(21.8 \%)\end{array}$ & 0.628 \\
\hline \multirow[t]{5}{*}{ ADG* score } & $0-3$ & $\begin{array}{l}134 \\
(13.1 \%)\end{array}$ & $387(13.4 \%)$ & $\begin{array}{l}134 \\
(13.1 \%)\end{array}$ & \multirow[t]{5}{*}{0.927} \\
\hline & $4-5$ & $\begin{array}{l}219 \\
(21.4 \%)\end{array}$ & $591(20.5 \%)$ & $\begin{array}{l}219 \\
(21.4 \%)\end{array}$ & \\
\hline & $6-7$ & $\begin{array}{l}250 \\
(24.4 \%)\end{array}$ & $689(23.9 \%)$ & $\begin{array}{l}250 \\
(24.4 \%)\end{array}$ & \\
\hline & $8-9$ & $\begin{array}{l}194 \\
(18.9 \%)\end{array}$ & $577(20.0 \%)$ & $\begin{array}{l}194 \\
(18.9 \%)\end{array}$ & \\
\hline & $10+$ & $\begin{array}{l}228 \\
(22.2 \%)\end{array}$ & $636(22.1 \%)$ & $\begin{array}{l}228 \\
(22.2 \%)\end{array}$ & \\
\hline \multirow[t]{5}{*}{$\begin{array}{l}\text { Income } \\
\text { Quintile }\end{array}$} & 1 & $\begin{array}{l}169 \\
(16.5 \%)\end{array}$ & $471(16.4 \%)$ & $\begin{array}{l}169 \\
(16.5 \%)\end{array}$ & \multirow[t]{5}{*}{0.673} \\
\hline & 2 & $\begin{array}{l}209 \\
(20.4 \%)\end{array}$ & $615(21.4 \%)$ & $\begin{array}{l}209 \\
(20.4 \%)\end{array}$ & \\
\hline & 3 & $\begin{array}{l}221 \\
(21.6 \%)\end{array}$ & $568(19.8 \%)$ & $\begin{array}{l}221 \\
(21.6 \%)\end{array}$ & \\
\hline & 4 & $\begin{array}{l}196 \\
(19.2 \%)\end{array}$ & $590(20.5 \%)$ & $\begin{array}{l}196 \\
(19.2 \%)\end{array}$ & \\
\hline & 5 (Highest) & $\begin{array}{l}228 \\
(22.3 \%)\end{array}$ & $631(21.9 \%)$ & $\begin{array}{l}228 \\
(22.3 \%)\end{array}$ & \\
\hline \multirow[t]{4}{*}{ Stage } & I & $\begin{array}{l}304 \\
(30.1 \%)\end{array}$ & $467(16.5 \%)$ & $\begin{array}{l}304 \\
(30.1 \%)\end{array}$ & $<0.001$ \\
\hline & II & $\begin{array}{l}505 \\
(50.0 \%)\end{array}$ & $1,532(54.0 \%)$ & $\begin{array}{l}505 \\
(50.0 \%)\end{array}$ & 0.025 \\
\hline & III & $\begin{array}{l}202 \\
(20.0 \%)\end{array}$ & $836(29.5 \%)$ & $\begin{array}{l}202 \\
(20.0 \%)\end{array}$ & $<0.001$ \\
\hline & Missing & $14(1.4 \%)$ & $45(1.6 \%)$ & $14(1.4 \%)$ & \\
\hline \multirow[t]{2}{*}{$\begin{array}{l}\text { Treatment } \\
\text { Group }\end{array}$} & Docetaxel & $\begin{array}{l}646 \\
(63.0 \%)\end{array}$ & $1,959(68.0 \%)$ & $\begin{array}{l}646 \\
(63.0 \%)\end{array}$ & 0.004 \\
\hline & Paclitaxel & $\begin{array}{l}365 \\
(35.6 \%)\end{array}$ & $899(31.2 \%)$ & $\begin{array}{l}365 \\
(35.6 \%)\end{array}$ & 0.01 \\
\hline
\end{tabular}


*ADG $=$ Aggregated Diagnosis Group

Table 2. Incidence of Prescription for Neuropathic Medication Within a Year of Chemotherapy Start Date Amongst Patients Treated With Any Taxane-based Regimen

\begin{tabular}{|lllll|}
\hline Outcome & Total & $\begin{array}{l}\text { Taxane }+ \\
\text { Trastuzumab }\end{array}$ & $\begin{array}{l}\text { Taxane } \\
\text { only }\end{array}$ & $\begin{array}{l}\text { P } \\
\text { value }\end{array}$ \\
\hline New prescription for neuropathic medication & $\begin{array}{l}12 \% \\
(468 / 3905)\end{array}$ & $\begin{array}{l}11.9 \% \\
(122 / 1025)\end{array}$ & $\begin{array}{l}12 \% \\
(346 / 2880)\end{array}$ & 0.93 \\
\hline $\begin{array}{l}\text { Second prescription for neuropathic } \\
\text { medication 6-12 months after first }\end{array}$ & $\begin{array}{l}4 \% \\
(131 / 3245)\end{array}$ & $\begin{array}{l}3.7 \% \\
(30 / 812)\end{array}$ & $\begin{array}{l}4.2 \% \\
(101 / 2433)\end{array}$ & 0.57 \\
\hline $\begin{array}{l}\text { Number of prescriptions for neuropathic } \\
\text { medication within 1 year, mean } \pm \text { SD }\end{array}$ & $3.24 \pm 3.85$ & $2.99 \pm 4.18$ & $3.32 \pm 3.73$ & 0.42 \\
& $(\mathrm{n}=468)$ & $(\mathrm{n}=122)$ & $(\mathrm{n}=346)$ & \\
\hline
\end{tabular}

Table 3. Incidence of Prescription for Neuropathic Medication Within a Year of Chemotherapy Start Date Amongst Patients treated with a Docetaxel-based Regimen

\begin{tabular}{|lllll|}
\hline Outcome & Total & $\begin{array}{l}\text { Docetaxel + } \\
\text { Trastuzumab }\end{array}$ & $\begin{array}{l}\text { Docetaxel } \\
\text { only }\end{array}$ & $\begin{array}{l}\text { P } \\
\text { value }\end{array}$ \\
\hline New prescription for neuropathic medication & $\begin{array}{l}8.6 \% \\
(224 / 2605)\end{array}$ & $9.9 \%(64 / 646)$ & $\begin{array}{l}8.2 \% \\
(160 / 1959)\end{array}$ & 0.17 \\
\hline $\begin{array}{l}\text { Second prescription for neuropathic } \\
\text { medication 6-12 months after first }\end{array}$ & $\begin{array}{l}2.7 \% \\
(61 / 2288)\end{array}$ & $2.5 \%(14 / 561)$ & $\begin{array}{l}2.7 \% \\
(47 / 1727)\end{array}$ & 0.77 \\
\hline $\begin{array}{l}\text { Number of prescriptions for neuropathic } \\
\text { medication within 1 year, mean } \pm \text { SD }\end{array}$ & $3.0 \pm 3.8$ & $2.59 \pm 2.67$ & $3.17 \pm 4.16$ & 0.31 \\
& $(\mathrm{n}=224)$ & $(\mathrm{n}=64)$ & $(\mathrm{n}=160)$ & \\
\hline
\end{tabular}

Table 4. Incidence of Prescription for Neuropathic Medication Within a Year of Chemotherapy Start Date Amongst Patients treated with a Paclitaxel-based Regimen 


\begin{tabular}{|lllll|}
\hline Outcome & Total & $\begin{array}{l}\text { Paclitaxel }+ \\
\text { Trastuzumab }\end{array}$ & $\begin{array}{l}\text { Paclitaxel } \\
\text { only }\end{array}$ & $\begin{array}{l}\text { P } \\
\text { value }\end{array}$ \\
\hline New prescription for neuropathic medication & $\begin{array}{l}18.9 \% \\
(239 / 1264)\end{array}$ & $\begin{array}{l}15.1 \% \\
(55 / 365)\end{array}$ & $\begin{array}{l}20.5 \% \\
(184 / 899)\end{array}$ & 0.026 \\
\hline $\begin{array}{l}\text { Second prescription for neuropathic } \\
\text { medication 6-12 months after first }\end{array}$ & $\begin{array}{l}7.3 \% \\
(68 / 930)\end{array}$ & $6.2 \%(15 / 242)$ & $\begin{array}{l}7.7 \% \\
(53 / 688)\end{array}$ & 0.44 \\
\hline $\begin{array}{l}\text { Number of prescriptions for neuropathic } \\
\text { medication within 1 year, mean } \pm \text { SD }\end{array}$ & $3.49 \pm 3.92$ & $3.55 \pm 5.49$ & $\begin{array}{l}3.48 \pm \\
3.34\end{array}$ & 0.91 \\
& $(n=239)$ & $(n=55)$ & $(n=184)$ & \\
\hline
\end{tabular}

Table 5. Relative Risk of Neuropathy Within a Year of Chemotherapy Start Date Amongst Patients treated with a Paclitaxel-based Regimen

\begin{tabular}{|c|c|c|c|c|c|}
\hline Variable & Level & Reference & Estimate & $95 \% \mathrm{Cl}$ & $\mathrm{Pr}>\mathrm{ChiSq}$ \\
\hline Herceptin & Yes & No & 0.78 & $0.6-1.1$ & 0.101 \\
\hline \multirow[t]{4}{*}{ ADG } & $4-5$ & $0-3$ & 0.71 & $0.5-1.1$ & 0.13 \\
\hline & $6-7$ & $0-3$ & 1.23 & $0.9-1.8$ & 0.282 \\
\hline & $8-9$ & $0-3$ & 1.14 & $0.8-1.7$ & 0.531 \\
\hline & $10+$ & $0-3$ & 1.16 & $0.8-1.7$ & 0.486 \\
\hline \multirow[t]{2}{*}{ Stage } & II & 1 & 1.35 & $0.9-2.0$ & 0.116 \\
\hline & III & I & 1.46 & $1.0-2.2$ & 0.066 \\
\hline Diabetes & Yes & No & 1.33 & $1.0-1.7$ & 0.038 \\
\hline \multirow[t]{4}{*}{ Income Quintile } & 1 & 5 & 1.59 & $1.0-2.4$ & 0.032 \\
\hline & 2 & 5 & 1.49 & $1.0-2.2$ & 0.051 \\
\hline & 3 & 5 & 1.57 & $1.1-2.4$ & 0.026 \\
\hline & 4 & 5 & 1.67 & $1.1-2.5$ & 0.013 \\
\hline
\end{tabular}

\section{Figures}




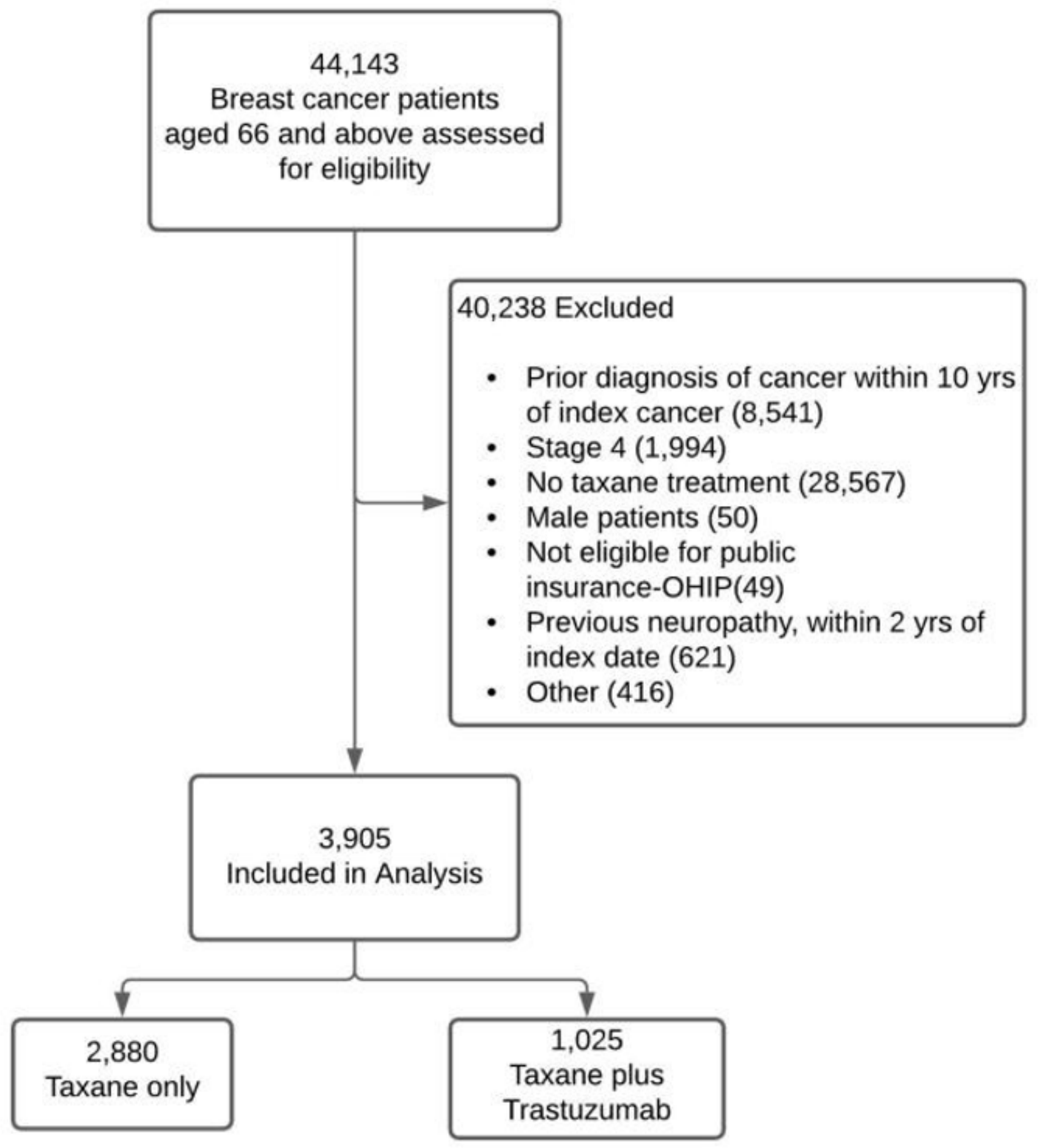

Figure 1

Flow diagram of study population indicating exclusion criteria and those included in analysis. 
Number of Outpatient Visits

a

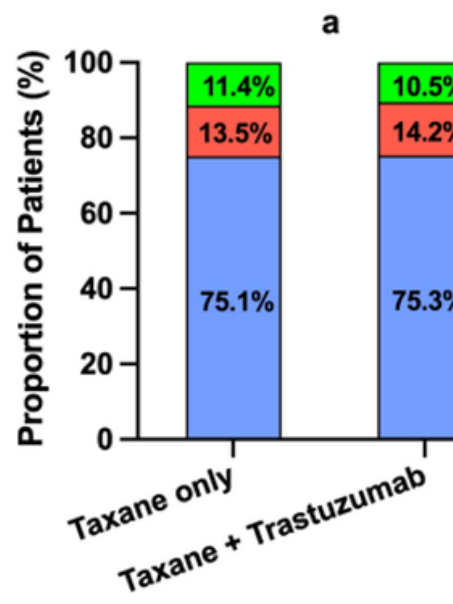

Number of ED Visits

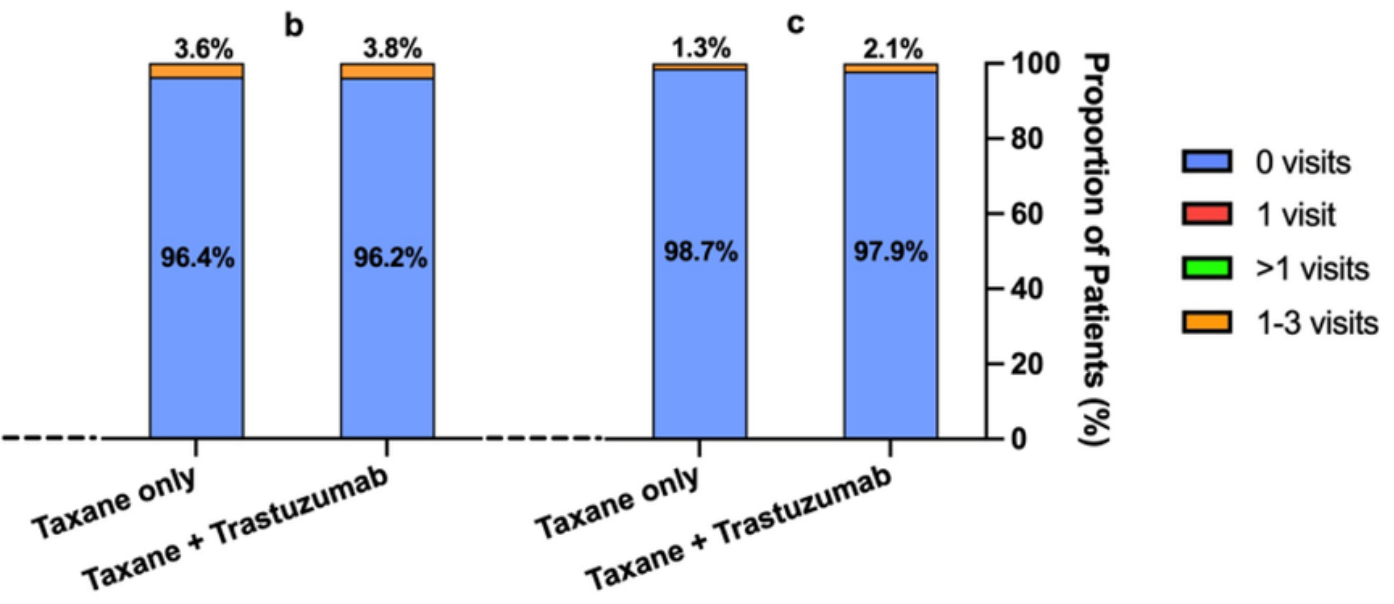

Figure 2

Healthcare utilization related to peripheral neuropathy amongst patients who received any taxane-based (docetaxel/paclitaxel) regimen. There was no difference identified in the cumulative number of visits to the (a) outpatient visits, (b) emergency department or (c) hospital admissions.

Number of Outpatient Visits
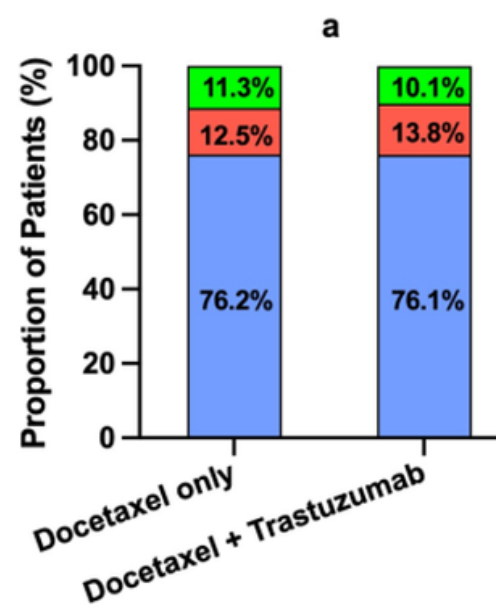

Number of ED Visits
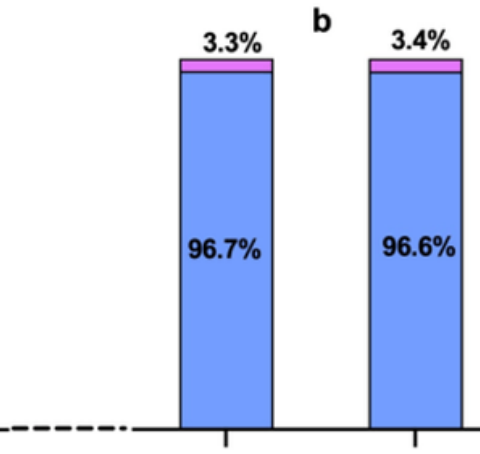

Number of Hospital Visits
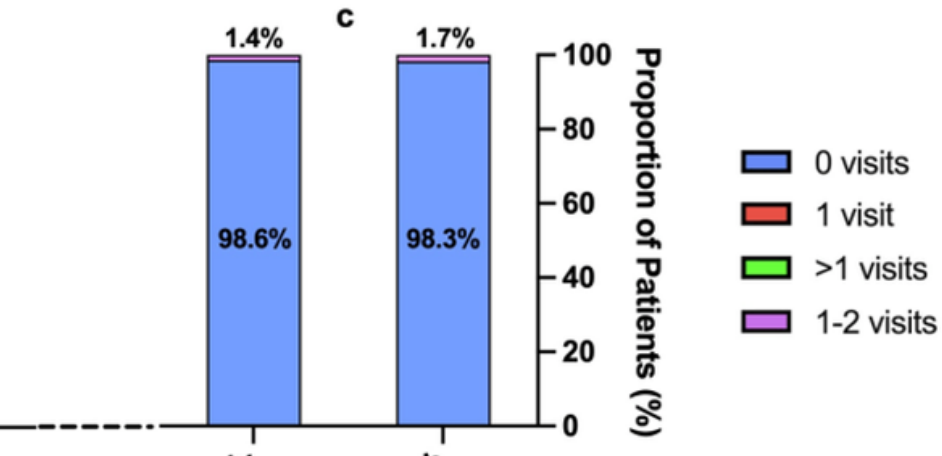

\section{Figure 3}

Healthcare utilization related to peripheral neuropathy amongst patients who received a docetaxel-based regimen. There was no difference identified in the cumulative number of (a) outpatient visits, (b) emergency department visits or (c) hospital admissions. 
Number of Outpatient Visits

a

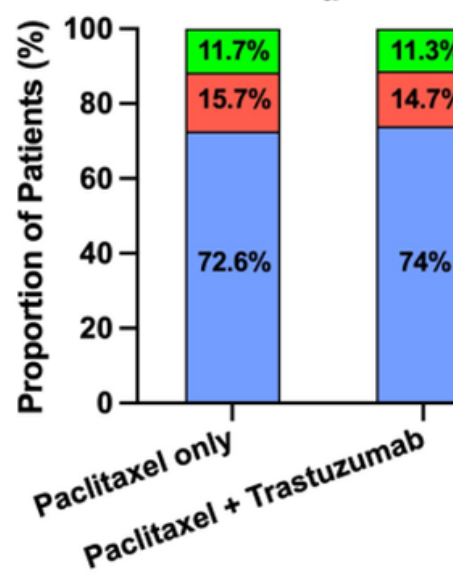

Number of ED Visits

b

$4.9 \%$

Number of Hospital Visits

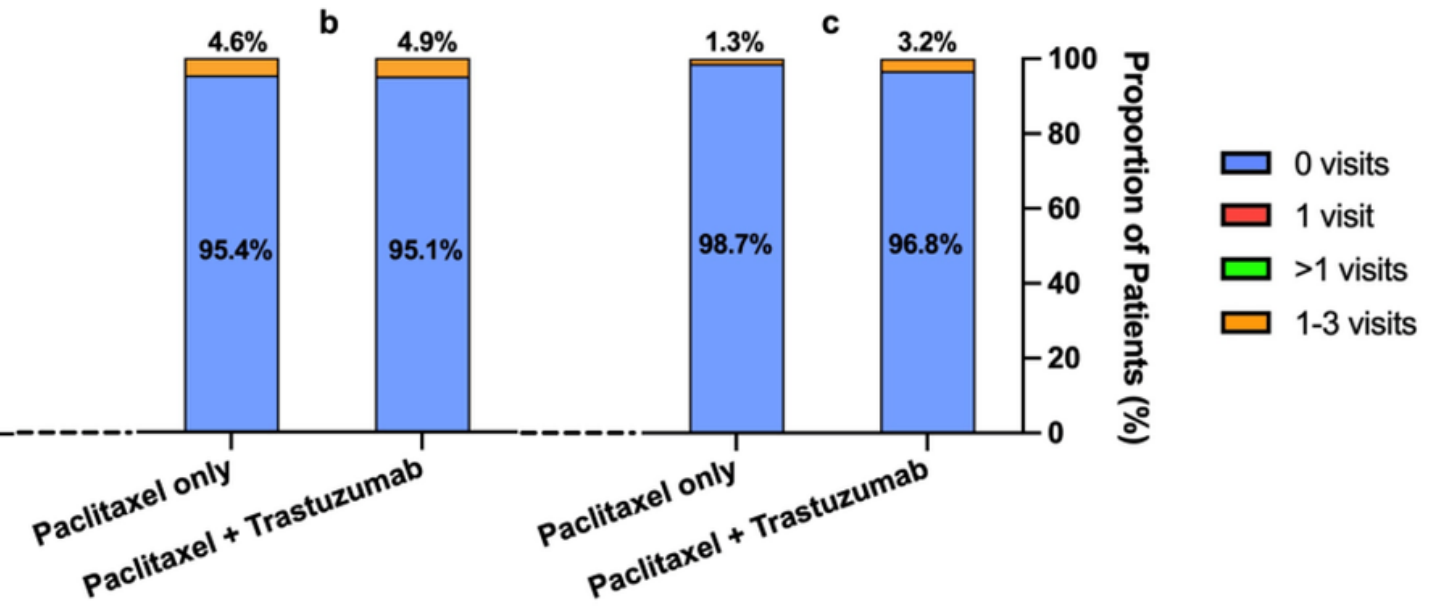

Figure 4

Healthcare utilization related to peripheral neuropathy amongst patients who received a paclitaxel-based regimen. There was no difference identified in the cumulative number of visits to the (a) outpatient visits, (b) emergency department or (c) hospital admissions. 